\title{
Uso do 5-Fluorouracil associado à cirurgia como terapêutica para o carcinoma de células escamosas em cães
}

\author{
5-Fluorouracil associated to surgery as a therapy for squamous cell carcinoma in dogs \\ Kelly Cristini Rocha da Silva Ferreira ${ }^{1}$, Rosemari Teresinha de Oliveira ${ }^{1,2}$, Cristiano Gomes ${ }^{3}$, \\ Anamaria de Oliveira Fernandes ${ }^{4}$, Carolina da Silva Cardoso ${ }^{4}$, Tuane Nerissa Alves Garcez ${ }^{4}$, \\ Andréa Faraon ${ }^{1} \&$ Luciana Oliveira de Oliveira ${ }^{1}$
}

\begin{abstract}
RESUMO
Ocarcinoma de células escamosas ou carcinoma epidermóide é uma neoplasia maligna de origem epidérmica. O5-fluorouracil é um agente antineoplásico comumente administrado pela via parenteral, também sendo descrito seu uso tópico em humanos. Este trabalho relata dois casos de carcinoma de células escamosas em cães que apresentavam nódulos na região abdominal ventral. Em ambos os casos, os animais foram submetidos à quimioterapia antineoplásica neoadjuvante com 5-fluorouracil, para reduzir o tamanho dos nódulos e facilitar a exérese dos mesmos. Em um dos pacientes, utilizou-se 5-fluorouracil pomada como tratamento local e, em outro, foi feita a administração por via endovenosa. Em ambos os casos, ocorreu remissão parcial dos tumores, a qual viabilizou a realização da cirurgia com maiores margens de segurança. Este estudo demonstra que o uso de 5-fluorouracil em cães é um procedimento seguro, devendo ser considerado em casos de tumores avançados, nos quais a cirurgia imediata não é possível.
\end{abstract}

Descritores: carcinoma de células escamosas, quimioterapia, cães.

\section{ABSTRACT}

The squamous cell carcinoma is a malignant neoplasm of epidermal origin. The 5-fluorouracil is an anticancer agent commonly administered by parenteral route, and its topical use in humans is also described. This paper reports two cases of squamous cell carcinoma in dogs that presented ventral nodes in the abdominal region. In both cases the animals were submitted to neoadjuvant antineoplastic chemotherapy with 5-fluorouracil to reduce the size of the nodules and then to surgery for the excision of the tumors. In one of the dogs, it was used a local 5-Fluorouracil and the other one was administrated intravenously. In both cases, partial remission of the tumors were observed, permitting surgery with larger margin of security. This study demonstrates that the use of 5-fluorouracil in dogs is safe and should be considered in cases of advanced tumors, in which immediate surgery is not possible.

Keywords: squamous cell carcinoma, chemotherapy, dog. 


\section{INTRODUÇÃO}

O carcinoma de células escamosas tem origem epidérmica e se apresenta geralmente como um tumor bem diferenciado, solitário e com superfície ulcerada [1]. Essa neoplasia geralmente ocorre em regiões anatômicas de pele clara e desprovidas de pelos que ficam expostas ao sol. O mecanismo envolvido no aparecimento das lesões solares é multifatorial e estas podem evoluir para o carcinoma de células escamosas [3]. Existem várias modalidades de tratamento para essa neoplasia, incluindo cirurgia, criocirurgia, radiação ionizante, quimioterapia e terapia fotodinâmica [8]. A escolha do tratamento depende do estadiamento do tumor, do estado geral do paciente e da disponibilidade de equipamentos e fármacos [5].

O 5-fluorouracil é um quimioterápico do grupo dos antimetabólitos que interfere na síntese de DNA e RNA por inibição enzimática. É comumente utilizado pela via parenteral, também sendo descrita a utilização local como pomada ou injeção intratumoral [4]. O custo da terapia com 5-fluorouracil tópico é relativamente baixo [6] e esse quimioterápico apresenta baixa toxicidade inespecífica, provocando apenas mielotoxicidade discreta. Entretanto, pode desencadear toxicidade neurológica de ocorrência aleatória no cão [4]. Em felinos, o uso de 5-fluorouracil é contraindicado.

Este trabalho tem o objetivo de relatar dois casos de carcinoma escamosocelular em cães, para os quais se utilizou o antineoplásico 5-fluorouracil como tratamento prévio à cirurgia.

\section{RELATO DE CASO}

Dois cães apresentando nódulo de pele, ambos na região abdominal ventral, foram encaminhados ao Setor de Oncologia Veterinária do Hospital de Clínicas Veterinárias da Universidade Federal do Rio Grande do Sul. O paciente I, raça Bull Terrier, macho,
9 anos de idade apresentava lesão ulcerada e dolorida, tendo surgido há 3 meses. O nódulo localizava-se lateralmente ao pênis e media $7 \mathrm{~cm}$ de diâmetro. $\mathrm{O}$ cão apresentava, também, lesões menores ao redor do nódulo principal, cujas dimensões variavam de 0,3 a $0,8 \mathrm{~cm}$ de diâmetro (Figura 1A). Ao exame clínico, o paciente apresentava normalidade dos parâmetros fisiológicos. Foi realizada biópsia aspirativa por agulha fina (BAAF) das lesões e exames ultrassonográfico abdominal e radiológico de tórax, além de hemograma e avaliação bioquímica das funções renal e hepática. Foi indicado tratamento quimioterápico com pomada de 5-fluorouracil ${ }^{1}$, a ser aplicada BID sobre a lesão durante 40 dias, com o objetivo de diminuir a área de ressecção. Foi recomendado ao proprietário do animal o uso de luvas durante as aplicações e uso de colar elizabetano no paciente (Figura 1B). Foram realizadas avaliações hematológicas e bioquímicas durante todo o tratamento quimioterápico. Posteriormente o animal foi encaminhado para a remoção cirúrgica do nódulo e o material foi submetido à análise histopatológica (Figura 1C).

O paciente II, sem raça definida, fêmea, 10 anos de idade, apresentava lesão ulcerada presente há 1 ano, medindo $13 \mathrm{~cm}$ de diâmetro, acompanhada de lesões menores que mediam entre 0,5 a $1 \mathrm{~cm}$ de diâmetro (Figura 2A). Ao exame clínico, o paciente apresentava-se indisposto e os linfonodos poplíteos estavam aumentados. Os nódulos eram pruriginosos, firmes à pal-pação, frouxamente aderidos e bastante irrigados. Realizou-se BAAF da lesão principal, hemograma e perfil bioquímico para avaliação das funções hepática e renal. Objetivando diminuir o tamanho do nódulo para menor área de exérese cirúrgica, foi realizado tratamento quimio-terápico com 5-fluorouracil ${ }^{2}$ em aplicações semanais, $150 \mathrm{mg} / \mathrm{m}^{2}$, por via endovenosa, durante 5 semanas (Figura $2 \mathrm{~B}$ ).

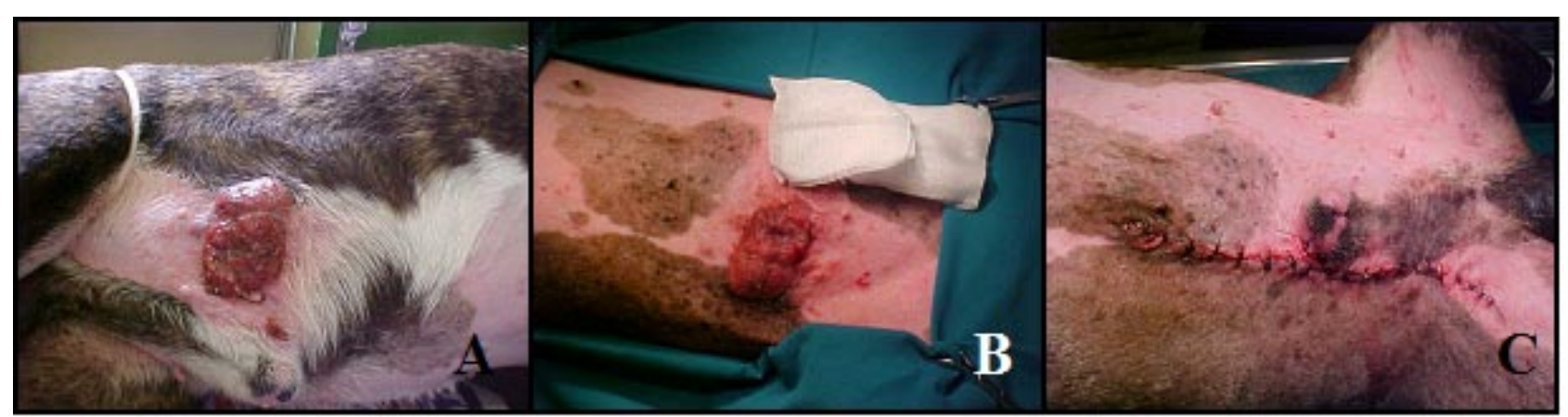

Figura 1. [A] Aspecto inicial da lesão de carcinoma de células escamosas em um canino, macho, Bull Terrier, 9 anos de idade. [B] Aparência da lesão após utilização do 5-fluorouracil tópico. [C] Aspecto após excisão tumoral. 


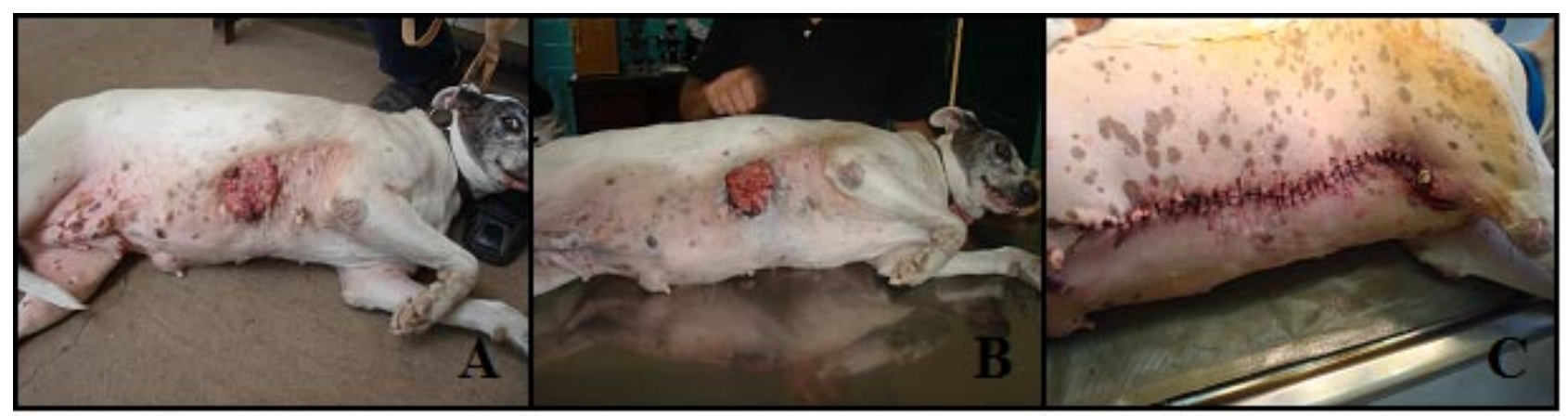

Figura 2. [A] Aspecto inicial da lesão de carcinoma de células escamosas em um canino, fêmea, SRD, 10 anos de idade. [B] Aparência da lesão após utilização do 5-fluorouracil sistêmico. [C] Aspecto após excisão tumoral.

Então, o paciente foi encaminhado à cirurgia, na qual foi coletado material para análise histopatológica ( $\mathrm{Fi}$ gura 2C). Ambos os pacientes foram acompanhados com revisões após o tratamento.

\section{DISCUSSÃO}

Os exames ultrassonográfico e radiológico realizados no paciente I não apresentaram alterações. O hemograma indicou leucocitose e a análise bioquímica, valor elevado de ALT. Optou-se por aplicação tópica de 5-fluorouracil, já que, por esta via, ocorre absorção sistêmica mínima [2]. A preparação de pomada para uso tópico na concentração de $5 \%$ é considerada ideal no que tange a possíveis efeitos tóxicos ou sistêmicos [7]. Após 40 dias de tratamento com o antineoplásico, observou-se diminuição da lesão principal em $20 \%$ e das lesões menores, em $80 \%$; porém, houve irritação na pele ao redor do tumor, de acordo com o encontrado na literatura [2]. Assim, o uso de 5fluorouracil foi interrompido. O exame citológico realizado a partir do material coletado por BAAF revelou diagnóstico sugestivo de carcinoma de células escamosas. Testes hema-tológicos e bioquímicos realizados durante o tratamento indicaram recuperação do padrão leucocitário e a função hepática permaneceu semelhante aos valores anteriores.

No paciente II, o hemograma e a análise bioquímica das funções renal e hepática encontraram-se dentro dos parâmetros normais e assim mantiveram-se durante o tratamento quimioterápico. Assim como no paciente I, a análise citológica do material coletado através de BAAF foi sugestiva de carcinoma de células escamosas. Após a primeira aplicação do medicamento, o animal apresentou-se mais disposto e houve diminuição do prurido na lesão. Ao término do tratamento, observou-se diminuição do nódulo principal em $20 \%$ e as lesões menores apresentaram redução de aproximadamente $60 \%$, havendo, porém, remissão completa dos nódulos de menor diâmetro.

O exame histopatológico confirmou o diagnóstico - obtido a partir do exame citológico - de carcinoma de células escamosas para ambos os casos, identificando metástase incipiente em linfonodo inguinal do paciente I. Nas revisões realizadas após a cirurgia, os dois animais apresentaram boa cicatrização, sem evidências de recidivas.

$\mathrm{O}$ uso de 5-fluorouracil em cães, como tratamento neoadjuvante à cirurgia para os casos de carcinoma de células escamosas, mostrou-se um procedimento seguro, devendo ser considerado nos casos de tumores de maiores dimensões ou disseminados, nos quais a correta técnica de ressecção cirúrgica fica prejudicada, bem como na prevenção das recidivas tumorais.

\section{NOTAS INFORMATIVAS}

${ }^{1}$ Efurixâ - ICN Farmacêutica Ltda. Campinas/SP, Brasil. ${ }^{2}$ Fluoruracila - Eurofarma Laboratórios Ltda. São Paulo/SP, Brasil.

\section{REFERÊNCIAS}

1 Dunn J.K. 2001. Tratado de Medicina de Pequenos Animais. São Paulo: Roca, 1075p.

2 Hardman J.G., Molinoff P.B., Rudonn R.W. \& Gilman A.G. 1996. As Bases Farmacológicas da Terapêutica. 9.ed. Rio de Janeiro: Mc Graw-Hill, 1436p.

3 Hargis A.M. 1990. Sistema tegumentar. In: Thomsom R.G. (Ed). Patologia Veterinária Especial. São Paulo: Manole, pp. 1-77.

4 Lanore D. \& Delprat C. 2004. Quimioterapia Anticancerígena. São Paulo: Roca, 228p. 
Ferreira K.C.R.S., Oliveira R.T., Gomes C., Fernandes A.O., Cardoso C.S., Garcez T.N.A., Faraon A. \& Oliveira L.0.2009.5-Fluorouracil associado à cirurgia como terapêutica para o carcinomia de células escamosas em cães. Acta ScientiaeVeterinariae. 37(1):89-92.

5 Moore A.S. \& Ogilvie G.K. 2001. Skin tumors. In: Ogilvie G.K. \& Moore A.S. (Eds). Feline Oncology. Trenton: Veterinary Learning Systems, pp. 398-428.

6 Patel G.K., Goodwin R., Chawla M., Laidler P., Price P.E., Finlay A.Y. \& Motley R.J. 2006. Imiquimod 5\% cream monotherapy for cutaneous squamous cell carcinoma in situ (Bowen's disease): A randomised double blind placebo controlled trial. Journal of the American Academy of Dermatology. 54: 1025-1032.

7 Sernick M. \& Lobato R.M.S. 1971. Tratamento de neoplascia cutânea pelo uso tópico e 5-fluorouracil. Anais brasileiros de dermatologia. 46: 25-25.

8 Straw R.C. 1998. Resection of the nasal planum. In: Bojrab M.J. (Ed). Current Techniques in Small Animal Surgery. 4th edn. Baltimore: Williams \& Wilkins, pp. 343-346. 